\title{
On The Determinants Of Relative Prices: Some Evidence From The Euro Area
}

\author{
Stephan Kienle, doctoral student, Darmstadt University of Technology, Germany
}

\begin{abstract}
Within the Balassa-Samuelson framework relative prices are exclusively driven by productivity gaps. The paper at hand suggests that sectoral taxation effects should additionally be taken into account. Such an enlargement of the classical approach is motivated by theory and confronted with real data for nine members of the Euro Area. We find empirical evidence for this extension indicating that both productivity and taxation should be regarded when changes in prices are analyzed.
\end{abstract}

Keywords: Relative Prices; Euro Area; Sectoral Taxation; Real Exchange Rates; Foreign Exchange Rates

\section{INTRODUCTION}

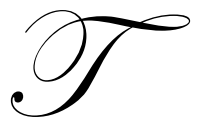

he seminal contributions of Balassa (1964) and Samuelson (1964) provide a framework for a still growing number of analyses which examine cross-country and cross-sector price developments. The basic intuition behind is that countries with relatively higher productivity growth rates in the tradable sector suffer from higher inflation rates than countries with lower productivity growth. This is because inflation is driven by the non-tradable sector where wage dynamics are equal as in the tradable one but productivity is lagging behind. The set up is often applied to assess whether and to what extent differences in productivity or related variables contribute to exchange rate movements. Among others, Rogoff (1996) explains the evolution of real exchange rates by differences in productivity gaps which are approximated by changes of real gross domestic product of the respective countries. More recently, a similar approach was pursued by Frankel (2005) who tackles the question whether and to what extent the Chinese Yuan might be undervalued against the US Dollar. Sinn and Reutter (2001) applied the Balassa-Samuelson framework to determine a minimum inflation rate for the Euro Area to avoid that one country suffers from deflation.

The concept is not only exploited in cross-country studies but also to explain price differences between both sectors - the tradable and the non-tradable one - within an economy. In this context it is often referred to the so called Baumol-Bowen effect, presented in the contribution by Baumol and Bowen (1966), which is dealing with crosssectoral inflation triggered by differences in productivity between the tradable and the non-tradable sector. This kind of application that is the one we focus on in what follows and can be found for instance in Kravis and Lipsey (1988) or De Gregorio et al. (1994).

In the paper at hand, we extend the approach by including taxation. The potential role of different taxation factors on output and thus on the relative prices of non-tradables is inspired by results presented by Nickell (2003) who models the effect of taxes on real wages. Against this background, we adapt the common theoretical approach and present a neoclassical model accounting for different tax effects in the tradable and the non-tradable goods sectors. Theory suggests that in the presence of taxation two determinants are relevant for the evolution of prices. In accordance with the classical approach, higher productivity growth in tradables compared to non-tradables leads to an increase in prices for non-tradables. A comparable effect is in addition observable for taxation being higher in the non-tradable sector than in the one producing tradable goods.

Theoretical implications are addressed in an empirical panel analysis based on data provided by the Organisation for Economic Co-operation and Development (OECD) which ensures a highly detailed degree of sectoral data. The sample comprises nine members of the Euro Area, i.e. Austria, Belgium, Estonia, Finland, France, 
Germany, Italy, the Netherlands and Spain. In contrast to the bulk of research using proxy variables for the evolution of productivity differences, we first estimate country-specific production functions for both sectors to calculate time series for productivity. Given the fact that national tax regimes substantially vary we do not rely on hardly comparable data on tax types and tax rates but also derive aggregate taxation per country and sector directly from the theoretical model.

We examine the classical relation and show that a relatively stronger growth in the productivity of tradables results in an increase in prices for non-tradables. Furthermore, we also test our hypothesis of a taxation effect on relative prices in an enlarged model. Again, our empirical findings are consistent with theory and intuition indicating that differences in the evolution of taxation between tradables and non-tradables can contribute to the explanation of relative prices and therefore affect real exchange rates.

The remainder of the paper is organized as follows: In section 2, we present a model of an open economy in order to derive the main implications of the Balassa-Samuelson framework taking national differences in taxation explicitly into account. In section 3, we confront our theoretical derivations with data on nine countries of the Euro Area and provide some empirical evidence in favor of our suggestion. Section 4 summarizes the main findings of the paper.

\section{THEORETICAL FOUNDATIONS}

\subsection{Set up of the model}

The intuition of the Balassa-Samuelson framework can easily be illustrated within a two-countries-twogoods environment. In each country one sector produces a tradable and a non-tradable good $\mathrm{T}$ and $\mathrm{N}$ respectively. Output $\mathrm{Y}$ of both sectors follows a country-specific constant-returns-to-scale production function depending on the level of productivity $\mathrm{A}$ and input factors capital $\mathrm{K}$ as well as labor $\mathrm{L}$ :

$$
\begin{aligned}
& Y_{T}=A_{T} F\left(K_{T}, L_{T}\right)=A_{T} L_{T} f\left(k_{T}\right) \\
& Y_{N}=A_{T} G\left(K_{N}, L_{N}\right)=A_{N} L_{N} g\left(k_{N}\right)
\end{aligned}
$$

As discussed above, we believe that taxation is a factor to be included. We therefore enlarge the framework and suggest that taxes are imposed by the government which could be set differently for both sectors. In each sector an arbitrary firm maximizes their time $t$ stock market value presented by $\mathrm{V}_{\mathrm{T}, \mathrm{t}}$ and $\mathrm{V}_{\mathrm{N}, \mathrm{t}}$ respectively, i.e.:

$$
\begin{aligned}
& \mathrm{V}_{\mathrm{T}, \mathrm{t}}=\sum_{\mathrm{s}=\mathrm{t}+1}^{\infty} \frac{1}{1+\mathrm{r}}^{\mathrm{s}-\mathrm{t}}\left[\theta_{\mathrm{T}, \mathrm{s}} \mathrm{A}_{\mathrm{T}, \mathrm{s}} \mathrm{F}\left(\mathrm{K}_{\mathrm{T}, \mathrm{s}}, \mathrm{L}_{\mathrm{T}, \mathrm{s}}\right) \mathrm{p}_{\mathrm{T}, \mathrm{s}}-\mathrm{w}_{\mathrm{s}} \mathrm{L}_{\mathrm{T}}-\mathrm{K}_{\mathrm{T}, \mathrm{s}+1}+\mathrm{K}_{\mathrm{T}, \mathrm{s}}\right] \\
& \mathrm{V}_{\mathrm{N}, \mathrm{t}}=\sum_{\mathrm{s}=\mathrm{t}+1}^{\infty} \frac{1}{1+\mathrm{r}}^{\mathrm{s}-\mathrm{t}}\left[\theta_{\mathrm{N}, \mathrm{s}} \mathrm{A}_{\mathrm{N}, \mathrm{s}} \mathrm{G}\left(\mathrm{K}_{\mathrm{N}, \mathrm{s}}, \mathrm{L}_{\mathrm{N}, \mathrm{s}}\right) \mathrm{p}_{\mathrm{N}, \mathrm{s}}-\mathrm{w}_{\mathrm{s}} \mathrm{L}_{\mathrm{T}}-\mathrm{K}_{\mathrm{N}, \mathrm{s}+1}+\mathrm{K}_{\mathrm{N}, \mathrm{s}}\right]
\end{aligned}
$$

where $r$ is the world interest rate, $p_{\mathrm{T}, \mathrm{s}}, \mathrm{p}_{\mathrm{N}, \mathrm{s}}$ are the prices of tradables and non-tradables and $\theta_{\mathrm{T}, \mathrm{s}}, \theta_{\mathrm{N}, \mathrm{s}}$ are taxation factors summarizing all distorting effects on output in the respective sector. Labor is assumed to be mobile both across sectors and countries leveling real wages, i.e. $\mathrm{w}_{\mathrm{T}, \mathrm{s}}=\mathrm{w}_{\mathrm{N}, \mathrm{s}}=\mathrm{w}$.

\subsection{Evolution of prices and real exchange rate}

Given that some standard assumptions hold - capital is mobile across countries and sectors, tradable goods can be transformed into capital, lending and borrowing is possible at the world interest rate $r$ - optimality conditions can be expressed by a set of four equations after maximizing the value of the firms with respect to capital and labor: 


$$
\begin{aligned}
& \theta_{\mathrm{T}, \mathrm{s}} \mathrm{p}_{\mathrm{T}, \mathrm{s}} \mathrm{A}_{\mathrm{T}, \mathrm{s}} \mathrm{f}_{\mathrm{T}}\left(\mathrm{k}_{\mathrm{T}, \mathrm{s}}\right)=\mathrm{r} \\
& \theta_{\mathrm{T}, \mathrm{s}} \mathrm{p}_{\mathrm{T}, \mathrm{s}} \mathrm{A}_{\mathrm{T}, \mathrm{s}}\left[\mathrm{f}\left(\mathrm{k}_{\mathrm{T}, \mathrm{s}}\right)-\mathrm{f}_{\mathrm{k}_{\mathrm{T}}}\left(\mathrm{k}_{\mathrm{T}, \mathrm{s}}\right) \mathrm{k}_{\mathrm{T}, \mathrm{s}}=\mathrm{w}_{\mathrm{s}}\right. \\
& \theta_{\mathrm{N}, \mathrm{s}} \mathrm{p}_{\mathrm{N}, \mathrm{s}} \mathrm{A}_{\mathrm{N}, \mathrm{s}} \mathrm{g}_{\mathrm{k}_{\mathrm{N}}}\left(\mathrm{k}_{\mathrm{N}, \mathrm{s}}\right)=\mathrm{r} \\
& \theta_{\mathrm{N}, \mathrm{s}} \mathrm{p}_{\mathrm{N}, \mathrm{s}} \mathrm{A}_{\mathrm{N}, \mathrm{s}}\left[\mathrm{g}\left(\mathrm{k}_{\mathrm{N}, \mathrm{s}}\right)-\mathrm{g}_{\mathrm{k}_{\mathrm{N}}}\left(\mathrm{k}_{\mathrm{N}, \mathrm{s}}\right) \mathrm{k}_{\mathrm{N}, \mathrm{s}}=\mathrm{w}_{\mathrm{s}}\right.
\end{aligned}
$$

Equations (5), (6) determine optimality conditions for the tradable goods sector, equations (7), (8) refer to the non-tradable goods sector.

Since the production function is homogenous of degree one the zero-profit condition leads to:

$$
\begin{aligned}
& \theta_{\mathrm{T}, \mathrm{s}} \mathrm{p}_{\mathrm{T}, \mathrm{s}} \mathrm{A}_{\mathrm{T}, \mathrm{s}} \mathrm{f}_{\mathrm{k}}\left(\mathrm{k}_{\mathrm{T}, \mathrm{s}}\right)=\mathrm{rk}_{\mathrm{T}, \mathrm{s}}+\mathrm{w}_{\mathrm{s}} \\
& \theta_{\mathrm{N}, \mathrm{s}} \mathrm{p}_{\mathrm{N}, \mathrm{s}} \mathrm{A}_{\mathrm{N}, \mathrm{s}} \mathrm{g}_{\mathrm{k}_{\mathrm{N}}}\left(\mathrm{k}_{\mathrm{N}, \mathrm{s}}\right)=\mathrm{rk}_{\mathrm{N}, \mathrm{s}}+\mathrm{w}_{\mathrm{s}}
\end{aligned}
$$

Taking natural logs and totally differentiating equations (9) and (10) yields to the following equation which in the absence of taxation is known as the Baumol-Bowen effect as further described by Baumol and Bowen (1966):

$$
\hat{\mathrm{p}}_{\mathrm{N}, \mathrm{s}}-\frac{\mu_{\mathrm{N}, \mathrm{s}}}{\mu_{\mathrm{T}, \mathrm{s}}} \hat{\mathrm{p}}_{\mathrm{T}, \mathrm{s}}=\frac{\mu_{\mathrm{N}, \mathrm{s}}}{\mu_{\mathrm{T}, \mathrm{s}}} \hat{\mathrm{A}}_{\mathrm{T}, \mathrm{s}}-\hat{\mathrm{A}}_{\mathrm{N}, \mathrm{s}}+\frac{\mu_{\mathrm{N}, \mathrm{s}}}{\mu_{\mathrm{T}, \mathrm{s}}} \hat{\theta}_{\mathrm{T}, \mathrm{s}}-\hat{\theta}_{\mathrm{N}, \mathrm{s}}
$$

where labor shares of income are expressed by $\mu_{\mathrm{L}, \mathrm{j}}$ for $\mathrm{j}=\mathrm{T}, \mathrm{N}$. For $\theta_{\mathrm{N}}=\theta_{\mathrm{T}}=1$, equation (11) coincides with the original Balassa-Samuelson relation. If the labor share of income in the sector for tradable goods is above the one in the other sector faster productivity growth for tradables will imply an increase in prices for non-tradables. In addition, different tax effects will also impact the relative price of non-tradables. For instance a higher relative tax effect in the sector for non-tradables would also result in an increase in the relative price of non-tradables.

Furthermore, differences in the evolution of taxes across countries would also impact the behavior of real exchange rates. We assume that price level is a geometric average of the prices of tradables and non-tradables where $y$ is the share of tradable goods and (1-y) the share of non-tradable goods. By normalizing the price of tradables to 1 and using equation (11) we get an enlarged Balassa-Samuelson relation:

$$
\hat{\mathrm{P}}-\hat{\mathrm{P}}^{*}=(1-\mathrm{y})\left[\frac{\mu_{\mathrm{T}}}{\mu_{\mathrm{N}}}\left(\hat{\mathrm{A}}_{\mathrm{T}}-\hat{\mathrm{A}}_{\mathrm{T}}^{*}\right)-\left(\hat{\mathrm{A}}_{\mathrm{N}}-\hat{\mathrm{A}}_{\mathrm{N}}^{*}\right)+\frac{\mu_{\mathrm{T}}}{\mu_{\mathrm{N}}}\left(\hat{\theta}_{\mathrm{T}}-\hat{\theta}_{\mathrm{T}}^{*}\right)-\left(\hat{\theta}_{\mathrm{N}}-\hat{\theta}_{\mathrm{N}}^{*}\right)\right]
$$

For the ease of notation, time indices are dropped; variables with an asterisk refer to a foreign country. Consequently, in the presence of taxation changes in the real exchange rate are not only driven by variation in total factor productivity as long as tax effects differ across countries. Or expressed in terms of monetary policy, the existence of substantial differences in fiscal policy could evoke inflation differences.

\section{EMPIRICAL EVIDENCE}

\subsection{Data description}

Our sample consists of yearly data from 1990 to 2008 for 9 countries comprising 21 sector-specific time series and is drawn from the OECD STAN database. Each sector is identified as tradable or non-tradable by its export-ratio defined as exports at current prices divided by the gross production at current prices. Following De Gregorio et al. (1994) a sector is classified as tradable when this ratio exceeds 10 per cent at least for two years of 
the sample period. Based on this heuristic all industries are classified as tradable that are attributed to A Agriculture, hunting and forestry, B - Fishing, C - Mining and quarrying or D - Manufacturing according to the standard industry list based on ISIC ((International Standard Industrial Classification of All Economic Activities) Rev. 3 which is the one also followed by the STAN database.

Output is given by value added, for which reason we do not include intermediate inputs on the right-hand side of equation (13) below. Capital is measured in terms of net capital stock; labor is represented by the number of full-time equivalents. Since full-time equivalents are not available for all countries but in some cases at least overall hours per worker and year, we use average weekly hours per worker provided by Eurostat to approximate full-time equivalents.

\subsection{Estimation of sectoral production functions and productivity}

Theory indicates the relevance of both changes in productivity and taxation for the evolution of price levels. Before both effects can be disentangled, time series for productivity changes are to calculate. We suppose a CobbDouglas production function to have the following form for each country $i$ and each sector $j$ at time $t$ :

$$
\ln \left(Y_{i, j, t}\right)=\ln \left(A_{i, j, t}\right)+\alpha_{k, i, j} \ln \left(K_{i, j, t}\right)+\alpha_{1, i, j} \ln \left(L_{i, j, t}\right)
$$

which is directly expressed in logs for the sake of simplicity. $\mathrm{Y}$ is again a measure of output, and $\mathrm{L}$ and $\mathrm{K}$ are the usage of capital and labor with output shares $\alpha_{k}$ and $\alpha_{1}$ respectively. The identification of the country-specific sectoral elasticities of labor and capital allows to rearrange terms of equation (13) and to derive time series for productivity.

To identify the elasticities the production function has to be estimated. The key problem in this context is a potential source of endogeneity of input factors such as capital or labor as pointed out by Griliches and Mareisse (1998). Hence, the observed inputs may be chosen as a function of unobserved determinants so that simple OLS estimates of the coefficients on the observed inputs would be biased. Among others, fixed effect estimations have been applied. Assuming unobserved determinants to be constant over time, the results are not very reliable. In recent decades, some new approaches developed. The first strand of literature focuses on dynamic panel data analysis, among others applied by Arellano and Bond (1991), Arellano and Bover (1995) and Blundell and Bond (2000). The second strand of literature applies somewhat like a control function approach. The basic idea has been developed by Olley and Pakes (1996). Similar procedures were subsequently proposed by Levinsohn and Petrin (2003) or Martin (2005).

Since the dynamic panel techniques mainly address the firm-level approach, i.e. large sample size but small time horizon, we concentrate on the second approach. But because the procedures proposed by Olley and Pakes (1996) and Levinsohn and Petrin (2003) may particularly suffer from collinearity problems as pointed out in Ackerberg et al. (2006) or similarly by Bond and Söderbom (2005), we decided to follow Ackerberg et al. (2006). The estimation procedure is further described in Annex A. Table 1 presents the country-specific elasticities of capital and labor:

Table 1: Sectoral elasticities of labor $\left(\alpha_{L}\right)$ and capital $\left(\alpha_{K}\right)$ per country ${ }^{1)}$

\begin{tabular}{|l|c|c|c|c|}
\hline \multirow{2}{*}{ Country } & \multicolumn{2}{|c|}{ Tradables } & \multicolumn{2}{c|}{ Non-Tradables } \\
\cline { 2 - 5 } & $\boldsymbol{\alpha}_{\mathbf{L}}$ & $\boldsymbol{\alpha}_{\mathbf{K}}$ & $\boldsymbol{\alpha}_{\mathbf{L}}$ & $\boldsymbol{\alpha}_{\mathbf{K}}$ \\
\hline Austria & 0.56 & 0.65 & 0.28 & 0.60 \\
\hline Belgium & 0.62 & 0.61 & 0.55 & 0.44 \\
\hline Estonia & 0.55 & 0.47 & 0.64 & 0.58 \\
\hline Finland & 0.64 & 0.43 & 0.57 & 0.61 \\
\hline France & 0.58 & 0.51 & 0.51 & 0.62 \\
\hline Germany & 0.39 & 0.45 & 0.62 & 0.40 \\
\hline Italy & 0.63 & 0.48 & 0.51 & 0.53 \\
\hline Netherlands & 0.61 & 0.65 & 0.61 & 0.41 \\
\hline Spain & 0.62 & 0.64 & 0.60 & 0.42 \\
\hline
\end{tabular}

1) All elasticities are significantly different from zero on a confidence level of $5 \%$. 


\subsection{Taxation and its effects on prices}

Based on the findings presented in the latter section we calculate the national tax effects. They can be disentangled using the optimality condition expressed in equation (6) and (8):

$$
\begin{aligned}
& \theta_{\mathrm{T}, \mathrm{t}} \mathrm{p}_{\mathrm{T}, \mathrm{t}} \mathrm{A}_{\mathrm{T}, \mathrm{t}}\left(1-\alpha_{\mathrm{k}, \mathrm{T}}\right) \mathrm{f}\left(\mathrm{k}_{\mathrm{T}}\right)=\mathrm{w}_{\mathrm{T}, \mathrm{t}} \\
& \theta_{\mathrm{N}, \mathrm{t}} \mathrm{p}_{\mathrm{N}, \mathrm{t}} \mathrm{A}_{\mathrm{N}, \mathrm{t}}\left(1-\alpha_{\mathrm{k}, \mathrm{N}}\right) \mathrm{g}\left(\mathrm{k}_{\mathrm{N}}\right)=\mathrm{w}_{\mathrm{N}, \mathrm{t}}
\end{aligned}
$$

Taking logs of equations (14) and (15), we can directly derive time series for taxation effects in both sectors. We are able to check whether or not the extended framework suggested by theory might be of empirical relevance. Based on equation (11) we estimate the following panel model:

$$
\begin{aligned}
\Delta \ln \left(\mathrm{P}_{\mathrm{N}, \mathrm{n}, \mathrm{t}}\right)-\frac{\alpha_{\mathrm{N}, \mathrm{n}}}{\alpha_{\mathrm{T}, \mathrm{n}}} \Delta \ln \left(\mathrm{P}_{\mathrm{T}, \mathrm{n}, \mathrm{t}}\right)= & \beta_{0}+\beta_{\mathrm{n}}+\beta_{1}\left[\frac{\alpha_{\mathrm{N}, \mathrm{n}}}{\alpha_{\mathrm{T}, \mathrm{n}}} \Delta \ln \left(\mathrm{A}_{\mathrm{T}, \mathrm{n}, \mathrm{t}}\right)-\Delta \ln \left(\mathrm{A}_{\mathrm{N}, \mathrm{n}, \mathrm{t}}\right)\right] \\
& +\beta_{2}\left[\frac{\alpha_{N, \mathrm{n}}}{\alpha_{\mathrm{T}, \mathrm{n}}} \Delta \ln \left(\theta_{\mathrm{T}, \mathrm{n}, \mathrm{t}}\right)-\Delta \ln \left(\theta_{\mathrm{N}, \mathrm{n}, \mathrm{t}}\right)\right]+\varepsilon_{\mathrm{n}, \mathrm{t}}+\rho_{\mathrm{t}}
\end{aligned}
$$

where $\beta_{0}$ and $\beta_{\mathrm{n}}$ are both time-invariant effects, but the latter one is specific for each country $\mathrm{n} ; \varepsilon$ and $\rho$ are stochastic error terms. For estimation purposes fixed country effects are supposed. Using a random effect estimator would not change results substantially. The results of a specification test suggested by Hausman (1978) indicate that there is no significant systematic difference in coefficients so that both fixed and random effects model shall be consistent, but the latter one is also efficient. However, we decided to keep to fixed effects, since we do not take time-constant covariates into account and thus favor the more general approach. ${ }^{1}$

Since the derivation of tax factors already comprises sectoral prices, the equation above may suffer from endogeneity resulting in biased estimates. We therefore use lagged variables of taxation factors for the estimation.

Results are presented in table 2. As a benchmark model - referred to as model I in what follows - we first exclusively estimate the effect of productivity on prices (19). We gain quite plausible results indicating the expected positive relation between a relatively faster productivity growth in the tradable goods sectors and an increase in the relative price of non-tradables. Furthermore, we present an estimate for the extended model - i.e. model II - allowing for both productivity and taxation effects on the relative price of non-tradables. Again, the effects are highly significant and consistent with our theoretical model derived above.

Table 2: Estimation results - full sample period (1990-2008) $)^{1)}$

\begin{tabular}{|l|c|c|}
\hline & Model I & Model II \\
\hline $\boldsymbol{\beta}_{\mathbf{0}}$ & $-0.02(0.01)$ & $-0.02(0.01)$ \\
\hline $\boldsymbol{\beta}_{\mathbf{1}}$ & $0.98(0.11)$ & $0.71(0.09)$ \\
\hline $\boldsymbol{\beta}_{\mathbf{2}}$ & & $0.39(0.04)$ \\
\hline
\end{tabular}

${ }^{1}$ Standard errors are given in parentheses

The models seem to be well specified. We perform a cross-correlation test as suggested by Pesaran (2004); since the null of cross-sectional independence could not be rejected on a common confidence level we do not have to correct standard errors for both models. Besides, our specifications seem to be free of autocorrelation according to a test based on Wooldridge (2002). All test results are shown in table 3.

\footnotetext{
1 The null of a Hausman's specification test cannot be rejected at a common confidence level: For model I and model II respectively we observe p-values of 0.47 and 0.32 .
} 
Table 3: Test results - full sample period $(1990-2008)^{1)}$

\begin{tabular}{|l|c|c|}
\hline & Model I & Model II \\
\hline Pesaran $^{2)}$ & $0.32(0.75)$ & $-0.88(0.38)$ \\
\hline Wooldridge $^{\text {3) }}$ & $0.13(0.73)$ & $0.01(0.91)$ \\
\hline
\end{tabular}

1) Test statistics with p-values in parentheses

${ }^{2)}$ Pesaran: H0: no cross-sectional dependence

${ }^{3)}$ Wooldridge: H0: no first-order autocorrelation

The results are quite robust against changing time horizon or country formation. As a robustness check we reduced the sample period and estimated both model I and model II based on data from 2000 and 2008. We obtain quite similar and still significant results as presented in table 4 .

Table 4: Estimation results - restricted sample period (2000-2008)*

\begin{tabular}{|l|c|c|}
\hline & Model I & Model II \\
\hline $\boldsymbol{\beta}_{\mathbf{0}}$ & $-0.02(0.01)$ & $-0.02(0.00)$ \\
\hline $\boldsymbol{\beta}_{\mathbf{1}}$ & $0.95(0.15)$ & $0.73(0.12)$ \\
\hline $\boldsymbol{\beta}_{\mathbf{2}}$ & & $0.38(0.06)$ \\
\hline
\end{tabular}

* Standard errors are given in parentheses

\section{CONCLUDING REMARKS}

Price developments and real exchange rates are crucial for the price competitiveness as well as trading behavior of countries and ultimately affect growth as pointed out for instance by Rodrik (2008). These issues became even more important when countries decide to form a currency union, since in this case the nominal exchange rates are irrevocably fixed among member countries and fluctuations in real figures are only driven by national price levels. Therefore, a thorough understanding of the determinants on prices is crucial.

In our paper we apply a classical framework to examine price developments. Following the contributions of Balassa (1964) and Samuelson (1964), productivity growth differentials between tradable and non-tradable goods are considered as an important determinant for the evolution of relative prices and thus for exchange rates. However, we enlarged the classic framework and introduce taxation as additional determinant of relative price developments and thus on the real exchange rates. Consequently, not only effects of different production conditions, i.e. the evolution of productivity, are relevant but also the fiscal environment influencing the production decision in the respective sector. Thus, our approach allows explaining the impact of taxation on relative prices within the BalassaSamuelson framework by amending the classical Baumol-Bowen effect.

We confront our theoretical considerations with data on nine Euro Area member countries. As Asea and Mendoza (1994) we do not rely on the often supposed relation between output per capita and domestic relative prices. We therefore use disaggregated data to calculate time series of productivity and taxation per country and sector. To generate these time series we apply a semi-parametric approach to identify country- and sector-specific production functions.

We are able to reveal the empirical relation according to which higher productivity in tradables yields to higher relative prices of non-tradables within a fixed-effect panel model. Following theoretical derivation, we also estimate an enlarged model taking taxation additionally into account. Align with intuition and theory, an increase in the tax burden of the sector for non-tradables relative to the one in the sector for tradables would raise the price for non-traded goods.

\section{ANNEX A}

For each country $\mathrm{i}$ and each sector $\mathrm{j}$, we consider the following Cobb-Douglas production function in logs for estimation purposes: 


$$
y_{i, j, t}=\alpha_{i, K, j} k_{i, j, t}+\alpha_{i, L, j} i_{i, j, t}+\eta_{i, j, t}+\varepsilon_{i, j, t}
$$

The notation is chosen similar to section 3.2: $\mathrm{y}$ measures value added, $\mathrm{k}$ and 1 represent capital and labor input with elasticities $\alpha_{\mathrm{K}}$ and $\alpha_{\mathrm{K}}$ as coefficients to estimate. Productivity is captured by two terms, $\eta$ and $\varepsilon$ respectively. While the first one is not observed by econometricians but known by the decision makers and therefore explicitly taken into account by firms when inputs are determined, the second one is an unknown error term which captures unanticipated shocks but also measurement errors. This procedure accounts for the issue usually referred to as the simultaneity problem, i.e. productivity is assumed to be at least partly observed by the firms before the input decision is made.

Following Levinsohn and Petrin (2003), we apply a semi-parametric approach to circumvent the simultaneity problem by using the demand function for intermediate inputs. In analogy to Ackerberg et al. (2006) labor is supposed to be less variable than these intermediates. Under this assumption, intermediate inputs $\mathrm{m}$ can be written as a function of labor 1 , capital $\mathrm{k}$ and the observed productivity effect $\eta$ :

$$
m_{i, j, t}=f\left(k_{i, j, t}, l_{i, j, t}, \eta_{i, j, t}\right)
$$

Inverting this function allows solving for $\eta$ and substituting this term in equation A.1, so that a first stage function $\psi$ can be defined:

$$
\psi\left(\mathrm{k}_{\mathrm{i}, \mathrm{j}, \mathrm{t}}, \mathrm{l}_{\mathrm{i}, \mathrm{j}, \mathrm{t}}, \mathrm{m}_{\mathrm{i}, \mathrm{j}, \mathrm{t}}\right)=\alpha_{\mathrm{i}, \mathrm{K}, \mathrm{j}} \mathrm{k}_{\mathrm{i}, \mathrm{j}, \mathrm{t}}+\alpha_{\mathrm{i}, \mathrm{L}, \mathrm{j}} \mathrm{l}_{\mathrm{i}, \mathrm{j}, \mathrm{t}}+\mathrm{f}^{-1}\left(\mathrm{k}_{\mathrm{i}, \mathrm{j}, \mathrm{t}}, \mathrm{l}_{\mathrm{i}, \mathrm{j}, \mathrm{t}}, \mathrm{m}_{\mathrm{i}, \mathrm{j}, \mathrm{t}}\right)+\varepsilon_{\mathrm{i}, \mathrm{j}, \mathrm{t}}
$$

which captures value added net of the error term $\varepsilon$ and and is in this paper approximated by a forth order polynomial. Note that in contrast to Levinsohn and Petrin (2003) or Olley and Pakes (1996) no coefficients for labor or capital are estimated in the first stage, since both are not identifiable. Given that productivity evolves as a Markov process, i.e.

$$
\eta_{i, j, t}=E_{t-1}\left[\eta_{i, j, t} \mid \eta_{i, j, t-1}\right]+v_{i, j, t}=g\left(\eta_{i, j, t-1}\right)+v_{i, j, t}
$$

we assume that the capital stock $\mathrm{k}_{\mathrm{t}}$ is already set at $\mathrm{t}-1$, so that it is independent of $v_{\mathrm{t}}$. This is not true for labor $\mathrm{l}_{\mathrm{t}}$ which is chosen in period $t$, but it is true for $1_{t-1}$. As suggested by Ackerberg et al. (2006) the second stage moment conditions result in:

$$
\begin{aligned}
& E_{t-1}\left[\eta_{i, j, t} \mid k_{i, j, t}\right]=0 \\
& E_{t-1}\left[\eta_{i, j, t} \mid 1_{i, j, t-1}\right]=0
\end{aligned}
$$

so that we are able to derive the elasticities $\alpha_{\mathrm{L}}$ and $\alpha_{\mathrm{K}}$ by non-linear least squares from the following equation:

$$
\begin{aligned}
y_{i, j, t}= & \alpha_{i, K, j} k_{i, j, t}+\alpha_{i, L, j} 1_{i, j, t}+g\left(\psi\left(l_{i, j, t-1}, k_{i, j, t-1}, m_{i, j, t-1}\right)\right. \\
& \left.-\alpha_{i, K, j} k_{i, j, t}+\alpha_{i, L, j} l_{i, j, t}\right)+v_{i, j, t} \varepsilon_{i, j, t}
\end{aligned}
$$

\section{AUTHOR INFORMATION}

Stephan Kienle is a doctoral student at the Darmstadt University of Technology. He did his undergraduate studies in business sciences and economics at the University of Applied Sciences of the Deutsche Bundesbank and at the Goethe University at Frankfurt, where he finally graduated with a Master equivalent degree in economics. His main research interest is in macroeconomics with a special focus on monetary policy. E-mail: stephan.kienle@stud.tudarmstadt.de. 


\section{REFERENCES}

1. Ackerberg, Daniel A., Caves, Kevin and Frazer, Garth (2006). Structural Identification of Production Functions, mimeo.

2. Arellano, Manuel and Bond, Stephen (1991). Some Tests of Specification for Panel Data: Monte Carlo Evidence and an Application to Employment Equations, Review of Economic Studies 58(2), 277-297.

3. Arellano, Manuel and Bover, Olympia (1995). Another Look at the Instrumental Variable Estimation of Error Components Models, Journal of Econometrics 68(1), 29-51.

4. Asea, Patrick and Mendoza, Enrique (1994). The Balassa-Samuelson Model: A General Equilibrium Appraisal, Review of International Economics 2(3), 244-267.

5. Balassa, Bela (1964). The purchasing power parity doctrine: A reappraisal, Journal of political Economy 72 (6), 584-596.

6. Baumol, William and Bowen, William (1964). Performing Arts: The Economic Dilemma, New York, 20th Century Fund.

7. Blundell, Richard and Bond, Stephen (2000). GMM estimation with persistent panel data: an application to production functions, Econometric Reviews 19(3), 321-340.

8. Bond, Stephan and Söderbom, Mans (2005). Adjustment Costs and the Identification of Cobb Douglas Production Functions, IFS Working Papers W05/04, Institute for Fiscal Studies.

9. De Gregorio, José, Giovannini, Alberto and Wolf, Holger C. (1994). International evidence on tradables and nontradables inflation, European Economic Review 38(6), 1225-1244.

10. Frankel, Jeffrey (2005). On the Renminbi, CESifo Forum 6(3), 16-21.

11. Griliches, Zvi and Mareisse, Jacques (1998). The search for identification, in Z. Griliches, Practicing Econometrics: Essays in Method and Application, Edward Elgar, Cheltenham, UK.

12. Hausman, Jerry A. (1978). Specification Tests in Econometrics, Econometrica 46(6), 1251-1271.

13. Kravis, Irving B. and Lipsey, Robert E. (1988). National Price Levels And The Prices Of Tradables And Nontradables, American Economic Review 78(2), 474-478.

14. Levinsohn, James and Petrin, Amil (2003). Estimating Production Functions Using Inputs to Control for Unobservables, The Review of Economics Studies 70(2), 317-341.

15. Martin, Ralf (2005). Computing the true spread, CEP Discussion Paper 0692.

16. Nickell, Stephen (2003). Employment and Taxes, CESifo Working Paper No. 1109.

17. Olley, Steven and Pakes, Ariel (1996). The Dynamics of Productivity in the Telecommunications Equipment Industry, Econometrica 64(6), 1263-1297.

18. Pesaran, M.Hashem (2004). General diagnostic tests for cross section dependence in panels, Cambridge Working Papers in Economics No 64.

19. Rodrik, Dani (2008). The Real Exchange Rate and Economic Growth, Brookings Papers on Economic Activity 2, 365-421.

20. $\quad$ Rogoff, Kenneth (1996). The Purchasing Power Parity Puzzle, Journal of Economic Literature 34, 647668.

21. Samuelson, Paul (1964). Theoretical notes on trade problems, Review on Economics and Statistics 46(2), 145-154.

22. Sinn, Hans-Werner and Reutter, Michael (2001). The Minimum Inflation Rate for Euroland, NBER Working Paper No. 8085.

23. Wooldridge, Jeffrey M. (2002). Econometric Analysis of Cross Section and Panel Data, Cambridge, MA: MIT Press. 